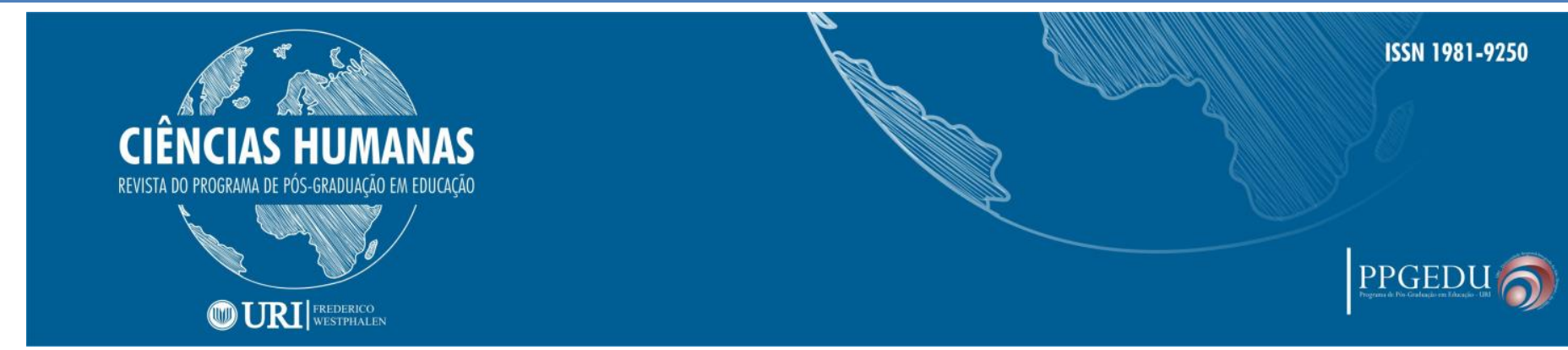

\title{
PROJETOS DE VIDA, UM CONCEITO EM CONSTRUÇÃO
}

\author{
LIFE PROJECTS, A CONCEPT IN CONSTRUCTION PROYECTOS DE VIDA, UN \\ CONCEPTO DE CONSTRUCCIÓN
}

\author{
Michela Augusta de Moraes e Sousa ${ }^{1}$; Maria Zenaide Alves ${ }^{2}$
}

\begin{abstract}
RESUMO
A noção de projetos de vida surge como uma categoria que busca explicar o fenômeno das decisões e escolhas dos indivíduos. De modo específico, alguns estudos têm se dedicado a pensar este conceito a partir da juventude, talvez pelo fato de que, no imaginário social, os jovens estão na fase da vida na qual ter projetos é basicamente uma obrigação. Esta foi a questão central que, inicialmente, orientou as reflexões contidas neste ensaio, que buscou discutir teoricamente a categoria projetos de vida, por meio de uma revisão bibliográfica de dissertações de mestrado disponíveis na BDTD. Interessa-nos especificamente compreender o que as pesquisas nos dizem sobre como essa categoria tem sido tratada no contexto educacional. $\mathrm{O}$ artigo se organiza buscando conhecer as concepções de projeto de vida presentes nas pesquisas analisadas, agrupando-as em categorias e observando os referenciais teóricos centrais nos quais se embasam a fim de compreender as interfaces construídas entre projetos de vida, juventude e escola.
\end{abstract}

PALAVRAS-CHAVE: Juventude; Projetos de vida; Ensino Médio.

\section{ABSTRACT}

The notion of life projects emerges as a category that seeks to explain the phenomenon of decisions and choices of the individuals. Specifically, some studies have been dedicated to thinking about this concept from youth, perhaps, because in the social imaginary, young people are at the stage of life in which having projects is basically an obligation. This was the central question that initially guided the reflections contained in this essay, which sought to theoretically discuss the category of life projects, through a literature review of master's dissertations available at BDTD. We are specifically interested in understanding what the researchs tells us about how this category has being treated in the educational context. The article is organized seeking to know the conceptions of life projects present in the analyzed researches, grouping them into categories and observing the main theoretical references in which they are based in order to understand the interfaces built between life projects, youth and school.

KEYWORDS: Youth; Life projects; High school.

\section{RESUMEN}

La idea de proyectos de vida surge como una categoría que busca explicar el fenómeno de las decisiones y elecciones de los individuos. Específicamente, algunos estudios se han dedicado a pensar en este concepto desde

\footnotetext{
${ }^{1}$ Licenciada em Letras pela Universidade Federal de Goiás, Especialista em Informática na Educação pela Universidade Federal de Lavras-MG, em Tecnologias em Educação pela Pontifícia Universidade Católica do Rio de Janeiro-RJ e em Gestão da Educação Pública pela Universidade Federal de Juiz de Fora-MG. Discente do Programa de Pós-Graduação em Educação - UFG-Regional Catalão. Docente da Rede Estadual de Ensino de Goiás.

${ }^{2}$ Docente do Programa de Pós-Graduação em Educação da Universidade Federal de Goiás (Campus Catalão). Coordenadora do Núcleo de Extensão e Pesquisa em Educação e Desenvolvimento do Campo (NEPCampo). Membro do programa Observatório da Juventude da UFMG.
}

\begin{tabular}{c|c|c|c}
\hline Rev. Ciências Humanas & Frederico Westphalen, RS & Pg. 145-165 & Maio/Agosto 2019 \\
\hline \multicolumn{2}{c}{ Recebido em: 10/06/2019 } & Aceito em: 16/08/2019 \\
\hline
\end{tabular}


la juventud, tal vez porque, en el imaginario social, los jóvenes están en la etapa de la vida en la que tener proyectos es básicamente una obligación. Esta fue la pregunta central que inicialmente guió las reflexiones contenidas en este ensayo, que buscaba discutir teóricamente los proyectos de vida de la categoría, a través de una revisión de literatura de disertaciones de maestría disponibles en BDTD. Estamos específicamente interesados en comprender lo que la investigación nos dice acerca de cómo se ha tratado esta categoría en el contexto educativo. El artículo está organizado buscando conocer las concepciones del proyecto de vida presentes en las investigaciones analizadas, agrupándolas en categorías y observando las referencias teóricas centrales en las que se basan para comprender las interfaces construidas entre proyectos de vida, juventud y escuela.

PALABRAS CLAVE: Juventud; Proyectos de vida; Escuela secundaria.

\section{CONSIDERAÇÕES INICIAIS}

Projetos sociais. Projetos educacionais. Projetos de lei. Projetos culturais. Projetos arquitetônicos. Projetos ambientais. Projetos de vida... independente da ação que se pretende desenvolver, qualquer conduta humana intencional tem como ponto de partida um projeto, um planejamento, por mais simples que seja. Este conceito, de caráter multidisciplinar, se aplica tanto a condutas individuais quanto coletivas e é analisado por Boutinet (2002) a partir das suas aplicações à educação, embora o autor forneça importantes elementos para a compreensão dos projetos em uma perspectiva ampliada. Analisando as origens do termo o autor afirma que, embora, seu surgimento possa datar do século XV, no sentido percebido hoje, é apenas no século XVII que é utilizado, ligado à arquitetura. Todavia, são os filósofos e pensadores do iluminismo, "época efervescente que mostrará toda sua sede de emancipação e progresso" (BOUTINET, 2002, p. 38) que começam a pensar o projeto no sentido compreendido hoje. Assim, projeto e progresso são elementos-chave para a construção dessa nova sociedade baseada no tempo técnico e não mais no tempo divino. $\mathrm{O}$ autor discute seu surgimento, na modernidade, seu percurso histórico e seu funcionamento na cultura tecnológica contemporânea, na qual o termo projeto tem se tornado mais presente, o autor revela "sua imposição quase generalizada na era pós-industrial" (op. Cit. p. 31). Assim, a noção de projeto ganha lugar de destaque nas produções filosóficas na primeira metade do século XX, embasado no conceito de intencionalidade, definida como "a propriedade de estabelecer com os objetos do seu meio uma relação intencional.” (BOUTINET, 2002p. 48).

Desse modo, se apreende que a noção de projeto, tal como utilizamos hoje, aplicado a diversas áreas para pensar as ações intencionais dos sujeitos, é uma invenção da modernidade quando, segundo Leite (2007), este novo elemento do projeto moderno de sociedade passa a \begin{tabular}{l|c|c|c}
\hline Rev. Ciências Humanas & Frederico Westphalen, RS & Pg. 145-165 & Maio/Agosto 2019 \\
\hline
\end{tabular} 


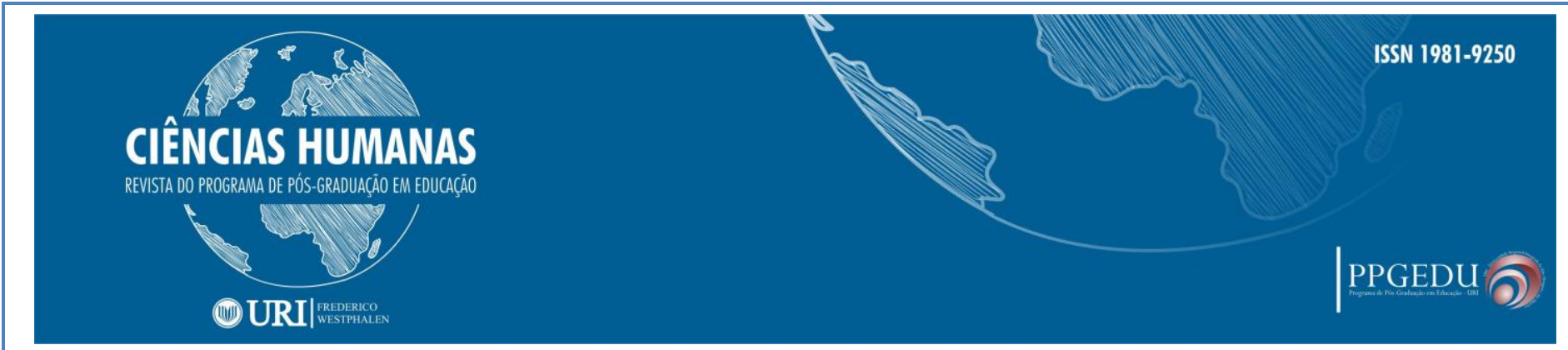

contribuir para esclarecer aspectos relativos à objetivação humana e a planificação da vida social. E neste sentido, na área da educação o projeto vem sendo concebido, na sua dimensão da organização das condutas humanas voltadas para todos os aspectos da vida individual e coletiva. A esta conduta mais ou menos organizada chamamos de projetos de vida e que também vem ganhando centralidade nos currículos escolares, sendo incorporado inclusive na matriz curricular de algumas escolas de Ensino Médio, como é o caso da rede estadual do estado de Goiás. Interessa-nos, neste artigo, analisar o que as pesquisas nos dizem sobre como essa categoria tem sido tratada na educação, em especial nas escolas de Ensino Médio, visto que, neste nível de ensino a questão dos projetos tem sido tratada com maior recorrência.

O conceito de projetos de vida não é um fenômeno natural carregado espontaneamente pelos indivíduos. Ele se constituiu dentro de um padrão cultural que passou a vigorar recentemente em nossa sociedade, permeado pelo aumento da expectativa de vida e somado aos vários avanços tecnológicos que permitiram aos indivíduos que o futuro pudesse ser moldado e mais bem aproveitado.

Partindo deste pressuposto, o termo projetos de vida se configura como uma construção social que atende a uma necessidade circunscrita a um modelo de sociedade, em que os indivíduos podem ter acesso ou não a esta concepção de organização de suas existências. (OLIVEIRA, 2015, p. 89)

Oliveira (2015) expõe que, de acordo com as mudanças no modelo de sociedade, os indivíduos se construíram como sujeitos e puderam também ter acesso ou não a concepção de como construir, moldar ou melhor aproveitar seus planos de existência. Nessa perspectiva houve um crescente interesse por compreender ou ajudar o desenvolvimento dos projetos de vida dos indivíduos, como forma de inseri-los conscientemente na sociedade. Esse interesse tem se tornado comum nas escolas, especialmente as de Ensino Médio, por trabalharem com (ou para) a juventude e por julgarem ser esse o momento considerado propício para a construção das escolhas de trajetória de vida. A categoria projetos de vida também vem despertando atenção, embora timidamente, dos estudiosos de diferentes áreas do conhecimento humano, como Psicologia, Sociologia, Filosofia, Administração e Educação. Tais pesquisas têm analisado a categoria no espaço escolar ou fora dele. Nos nossos estudos temos buscado compreender o conceito a partir da abordagem educacional e como ele tem 


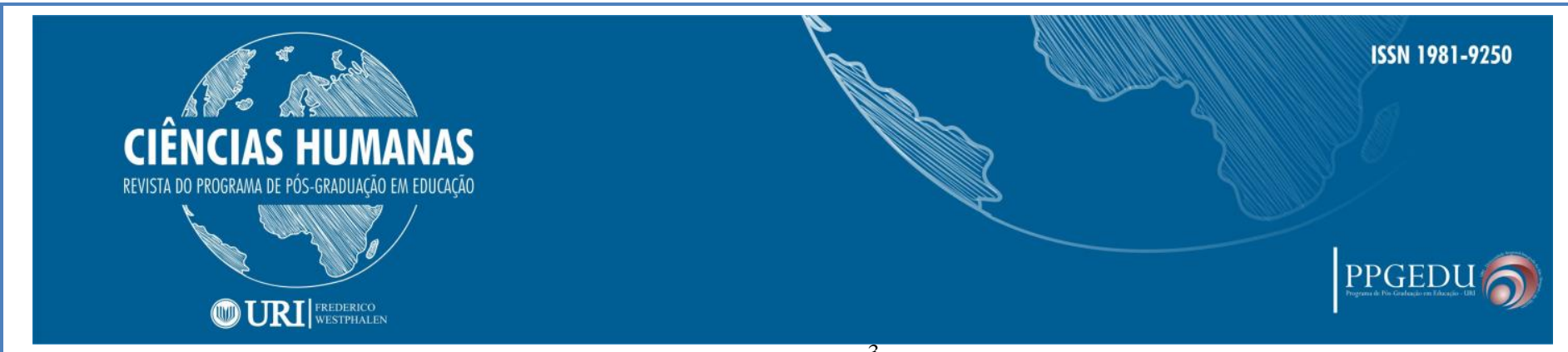

sido inserido dentro das escolas de Ensino Médio ${ }^{3}$. A nossa concepção de projetos de vida se consolida na visão socioantropológica, concebendo os projetos de vida como algo que vai além de um ideal, um plano, uma meta, mas como resultado das implicações de toda uma construção de vida onde a condição social, os valores, os espaços e instituições em que o jovem convive e que vão dar suporte ao jovem nas suas condutas e escolhas presentes e futuras, traçadas dentro do seu campo de possibilidades (VELHO, 2003).

A partir desse entendimento consideramos que compreender a relação entre projetos de vida, juventude e Ensino Médio é tarefa fundamental, por ser uma fase da vida onde as decisões e as escolhas parecem inquietar os sujeitos mais que em outros momentos da vida, além de ser um momento da vida no qual os sujeitos se defrontam com muitas cobranças da sociedade. Quem nunca ouviu, em muitos casos ainda na infância, perguntas do tipo "o que você vai ser quando crescer?

\section{PERCURSO METODOLÓGICO}

Para construir nosso material de análise utilizamos como metodologia a pesquisa bibliográfica na (BDTD) Base Digital Brasileira de Teses e Dissertações buscando trabalhos que discorressem sobre o tema projetos de vida e juventude, de maneira especial, no contexto do Ensino Médio, sem recorte temporal. O processo envolveu a formação de uma base de dados preliminares, por meio da aplicação de filtro com as palavras chaves: projetos de vida, juventude e ensino médio, com o objetivo de buscar as pesquisas que convergissem com o tema em discussão. Ao buscar esses dados preliminares, encontramos 60 trabalhos entre Teses e Dissertações que discutiam o tema projetos de vida voltado para a juventude dentro do ensino médio. Temos ciência de que nos limites deste manuscrito não daríamos conta de analisar todos os trabalhos produzidos sobre o assunto, assim, optamos pela BDTD por ser um repositório com grande número de Teses e Dissertações nas mais variadas áreas do conhecimento e optamos apenas pelas Dissertações dado o elevado número de trabalhos encontrados.

\footnotetext{
${ }^{3}$ Este estudo em andamento faz parte da dissertação de Mestrado em Educação intitulado: JUVENTUDE E PROJETOS DE VIDA EM UMA ESCOLA EM TEMPO INTEGRAL DE ATALÃO-GO, que reflete os projetos de vida na perspectiva dos jovens estudantes do Ensino Médio de um CEPI (Centro de Ensino em Período Integral).
}

\begin{tabular}{l|c|c|c}
\hline Rev. Ciências Humanas & Frederico Westphalen, RS & Pg. 145-165 & Maio/Agosto 2019
\end{tabular}

\begin{tabular}{l|l} 
Recebido em: 10/06/2019 & Aceito em: 16/08/2019
\end{tabular}




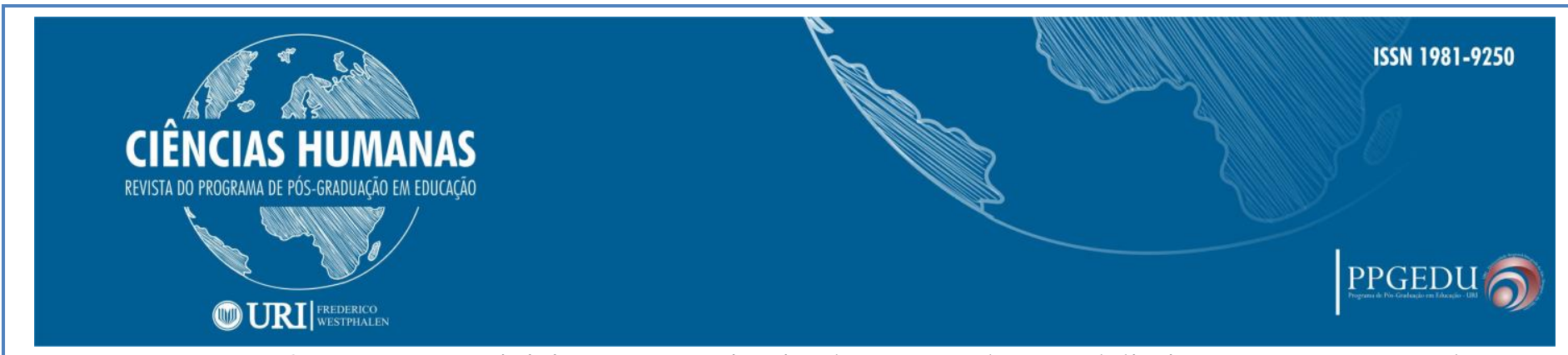

$\mathrm{O}$ processo se iniciou numa primeira busca geral, sem delimitar recorte temporal e utilizando as palavras projetos de vida, sem o uso das aspas, onde encontramos um total de 9.630 trabalhos entre Teses e Dissertações. Lendo alguns títulos desses trabalhos, percebemos que o resultado da busca se deu em associação direta a palavra projeto, portanto com muitos títulos tratando a respeito de Projetos de lei, Projetos de casa, Projetos de limpeza, entre outros. Realizamos, então, uma segunda busca utilizando aspas e associando projetos de vida, juventude e ensino médio. Nessa segunda busca encontramos 60 Teses e Dissertações e já percebemos pelos títulos que os trabalhos começavam a se aproximar do nosso objeto de pesquisa. Fizemos, então, uma terceira busca optando apenas por Dissertações e tivemos resultados possíveis de análise, pela quantidade e proximidade com nossas pesquisas.

Assim, foram selecionadas 38 Dissertação de Mestrado, sem recorte temporal, de várias áreas do conhecimento, utilizando as palavras chaves: projetos de vida, juventude e ensino médio associadas. Lendo os resumos destas pesquisas, selecionamos 30 delas para leitura geral, por estarem mais próximas das questões que queríamos compreender. Das 30 dissertações encontradas, 14 nos chamaram a atenção de maneira especial por terem o foco na discussão e construção teórica de projetos de vida na juventude, no ambiente escolar e sob diferentes perspectivas. Assim esta análise foi construída com base nessas Dissertações: 


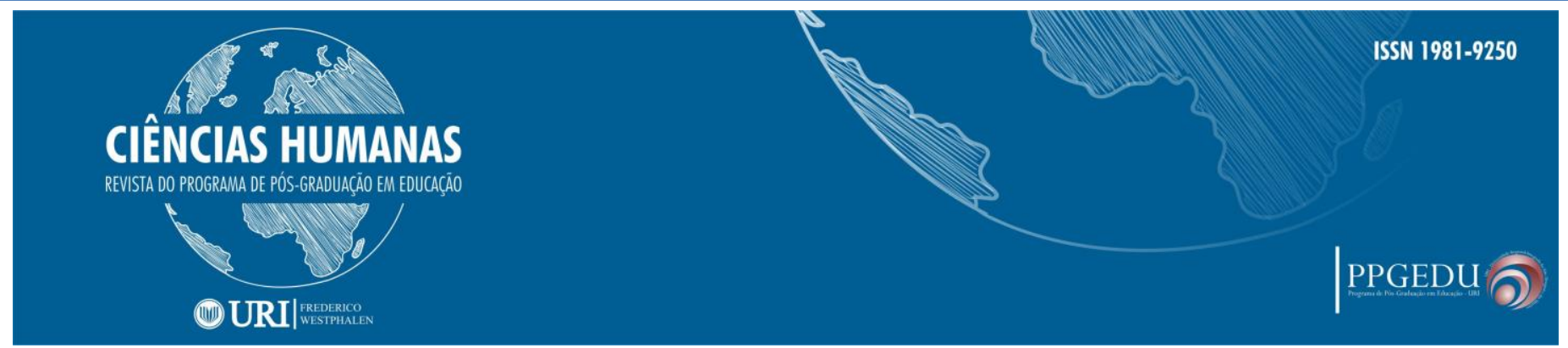

QUADRO 1 - Dissertações analisadas

\begin{tabular}{|c|c|c|c|c|}
\hline Títulos & Autores & $\begin{array}{l}\text { Ano de } \\
\text { defesa }\end{array}$ & Instituições & Programa \\
\hline $\begin{array}{l}\text { 01-Projetos de vida e projetos vitais: um estudo sobre } \\
\text { projetos de jovens estudantes em condição de } \\
\text { vulnerabilidade social da cidade de São Paulo }\end{array}$ & \begin{tabular}{|l|} 
Daniela \\
Haertel \\
Hurtado
\end{tabular} & 2012 & $\begin{array}{l}\text { Faculdade de } \\
\text { Educação } \\
\text { USP }\end{array}$ & Educação \\
\hline $\begin{array}{l}\text { 02-Do virtual ao real: implicações da internet nos projetos } \\
\text { de vida do adolescente }\end{array}$ & $\begin{array}{l}\text { Clécia } \\
\text { Lorena do } \\
\text { Amaral } \\
\text { Shibuya } \\
\end{array}$ & 2012 & UNICAMP & Psicologia \\
\hline $\begin{array}{l}\text { 03-Juventude e projetos de futuro: possibilidades e } \\
\text { sentidos do trabalho para os estudantes do Instituto } \\
\text { Federal de Educação, Ciência e Tecnologia do Espirito } \\
\text { Santo (Ifes) }\end{array}$ & \begin{tabular}{|l|} 
Terezinha \\
de Jesus \\
Lyrio \\
Loureiro \\
\end{tabular} & 2013 & UFES & Psicologia \\
\hline $\begin{array}{l}\text { 04-Os desafios e limites na construção do projeto } \\
\text { profissional dos jovens que frequentam o ensino médio } \\
\text { público e privado }\end{array}$ & \begin{tabular}{l|} 
Camila \\
Ferreira \\
Lopes Paiva \\
\end{tabular} & 2013 & UNESP & Educação \\
\hline $\begin{array}{l}\text { 05-Projetos de vida e educação moral: um estudo na } \\
\text { perspectiva da teoria dos modelos organizadores do } \\
\text { pensamento }\end{array}$ & $\begin{array}{l}\text { Cebel Danza } \\
\text { Hanna }\end{array}$ & 2014 & $\mathrm{FE} / \mathrm{USP}$ & Educação \\
\hline $\begin{array}{l}\text { 06-Na terra da luz: o sol nasce para todos, mas a sombra } \\
\text { é para poucos. Projetos de vida e campo de possibilidades } \\
\text { de jovens das classes populares }\end{array}$ & $\begin{array}{l}\text { Antonia } \\
\text { Aleksandra } \\
\text { Mendes } \\
\text { Oliveira } \\
\end{array}$ & 2015 & UFC & Sociologia \\
\hline $\begin{array}{l}\text { 07-O amanhã de quem cresce: influências e valores } \\
\text { presentes na constituição de projetos de vida de jovens } \\
\text { adolescentes de um curso técnico de uma instituição } \\
\text { estadual }\end{array}$ & $\begin{array}{l}\text { Junior, } \\
\text { Gilberto } \\
\text { Luiz } \\
\text { Mattielo }\end{array}$ & 2015 & UNESP & $\begin{array}{l}\text { Filosofia } \\
\text { da } \\
\text { Educação }\end{array}$ \\
\hline $\begin{array}{l}\begin{array}{l}\text { 08-O projeto de vida no ensino médio: } \\
\text { professores de História }\end{array} \\
\end{array}$ & \begin{tabular}{|l|} 
Sandra \\
Maria Fodra \\
\end{tabular} & 2016 & PUC - SP & Educação \\
\hline $\begin{array}{l}\text { 09-Percursos e projetos de vida das juventudes egressas } \\
\text { da escola do campo }\end{array}$ & $\begin{array}{l}\text { Kamila } \\
\text { Costa, } \\
\text { Sousa } \\
\end{array}$ & 2016 & UFC & Educação \\
\hline $\begin{array}{l}\text { 10-Projetos de vida e estima de lugar: um estudo com } \\
\text { jovens adolescentes de escolas públicas de Fortaleza/CE }\end{array}$ & $\begin{array}{l}\text { Debora } \\
\text { Linhares } \\
\text { Silva } \\
\end{array}$ & 2016 & UFC & Psicologia \\
\hline $\begin{array}{l}\text { 11-Escola, consumo e projetos de vida na visão de jovens } \\
\text { estudantes de uma escola pública e outra privada no } \\
\text { interior do estado de São Paulo }\end{array}$ & $\begin{array}{l}\text { Anderson } \\
\text { Cinati }\end{array}$ & 2016 & UFSCAR & Educação \\
\hline $\begin{array}{l}\text { 12-Projeto de vida e ENEM: uma análise do questionário } \\
\text { socioeconômico e suas implicações para o ensino médio }\end{array}$ & \begin{tabular}{|l|} 
Tiago \\
Ribeiro \\
Anjos \\
\end{tabular} & 2017 & UFSCAR & Educação \\
\hline $\begin{array}{l}\text { 13-Escolhas possiveis em futuros incertos: a escola e a } \\
\text { construção do projeto de vida profissional nal } \\
\text { adolescência }\end{array}$ & \begin{tabular}{|l|} 
Alexandre \\
Bernardo da \\
Silva \\
\end{tabular} & 2017 & UNINOVE & Educação \\
\hline $\begin{array}{l}\text { 14-Formação, projetos profissionais e } \\
\text { projetos de vida: olhares dos estudantes do curso de } \\
\text { técnico em administração integrado ao ensino médio do } \\
\text { IFPI - Campus de São Raimundo Nonato }\end{array}$ & $\begin{array}{l}\text { Geuid } \\
\text { Cavalcante } \\
\text { Silva Filho }\end{array}$ & 2018 & UNINOVE & Educação \\
\hline
\end{tabular}

Construção autoral 


\section{PROJETOS DE VIDA: CONCEPÇÕES, ABORDAGENS E FUNDAMENTOS}

O quadro acima nos revela que as pesquisas com o tema dos projetos de vida se concentram especialmente na Educação. Este é um dado relevante por evidenciar que, se as escolas estão introduzindo o tema projetos de vida dentro do seu espaço, as pesquisas educacionais precisam tomar esse tema como objeto de suas pesquisas.

Outro aspecto a ser observado é a concentração de pesquisas em poucas instituições do Nordeste e Sudeste. Ainda são poucos os pesquisadores a se dedicarem ao tema projetos de vida. Poderia a análise das Teses revelar uma ampliação deste dado, mas em nível de Mestrado as pesquisas se concentram basicamente em oito instituições. Isso nos leva a refletir sobre a preocupação dos pesquisadores com esse tema que vem se destacando recentemente no cenário das formações dos sonhos e ideais de vida, especialmente na vida dos jovens. Todavia, fica evidente se tratar de uma temática emergente, visto que, as primeiras pesquisas datam do ano de 2012 e ainda há muito a se explorar sobre o tema.

\section{Os projetos de vida e a perspectiva profissional}

Uma das formas mais comuns de conceber o estudo dos projetos de vida é identificá-lo a partir da escolha da vida profissional, ou seja, é como se quando se falasse em projetos de vida este se resumisse aos projetos profissionais. A dissertação de Sandra Maria Fodra, defendida em 2016, em São Paulo, na PUC, intitulada "O projeto de vida no ensino médio: o olhar dos professores de História", teve como objetivo levantar os aspectos positivos e os desafiadores do Programa Ensino Integral, bem como do componente curricular Projeto de Vida e sua relação com as aulas de História, na visão dos Professores de História que também lecionam aulas de Projeto de Vida no Ensino Médio. O Programa Ensino Integral foi implantado pela Secretaria Estadual de São Paulo, em 2012, em 16 escolas públicas piloto. As escolas participantes deste projeto almejavam a excelência acadêmica e o desenvolvimento da autonomia dos alunos. O foco dessas escolas seria o componente curricular Projeto de Vida onde os jovens seriam preparados para fazerem escolhas conscientes, tanto na vida 


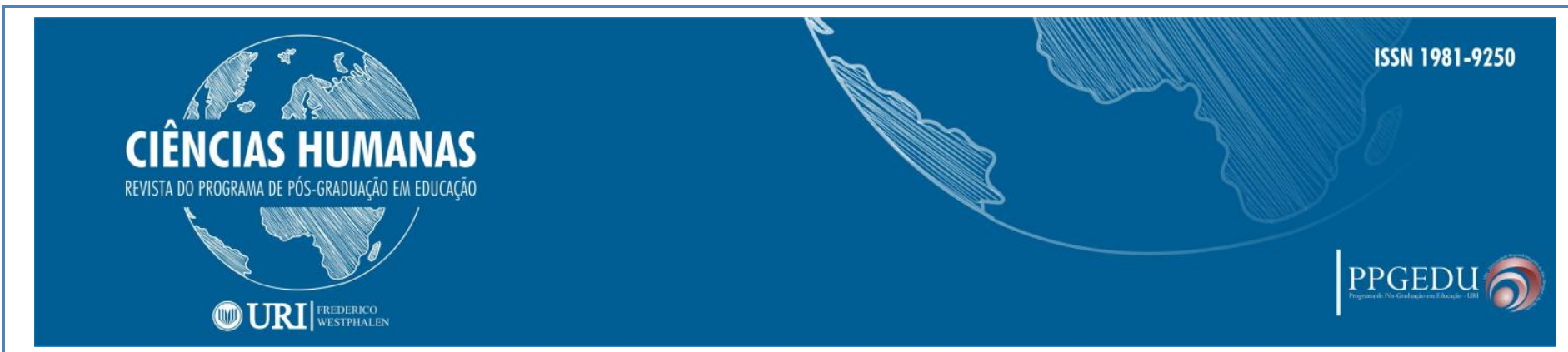

acadêmica, como em outras áreas da vida. A autora discute essas escolhas, mas sempre sob a ótica da disciplina Projeto de Vida. A autora compreende que, mesmo a disciplina Projeto de Vida tentando fazer um "resgate na noção de direitos e deveres que favorecem a formação de uma cidadania participativa" (Fodra, 2016, p. 8) e contribuindo para a inserção do jovem na vida adulta, de forma consciente e responsável, como profissional e sujeito participante, ela acaba se direcionando para as escolhas profissionais dos alunos com o foco principal na formação de jovens aptos para o ambiente de trabalho. Assim a concepção de projetos de vida identificada nas construções da autora, rememoram uma preparação para as escolhas da vida, em como o jovem pode se compreender como sujeito na construção de suas escolhas, mas também, leva em consideração que essa formação precisa estar de acordo com as exigências do mercado de trabalho.

Nesta mesma perspectiva encontramos a dissertação de Alexandre Bernardo Silva, defendida em 2017, em São Paulo, na UNINOVE, intitulada "Escolhas possíveis em futuros incertos: a escola e a construção do projeto de vida profissional na adolescência". Esta dissertação teve o objetivo de "compreender qual o papel da escola na construção do projeto de vida profissional do adolescente no ensino médio" (Silva, 2017, p. 9). Traz a concepção de projetos de vida numa perspectiva estritamente profissional diferenciando-se de alguns autores que constroem suas concepções numa perspectiva que identifica os projetos de vida na constituição total do sujeito e não apenas como uma parte dele (Alves 2013, 2015; Dayrell 2013; León 2005). No entanto, Silva (2017) aprofunda sua análise, fazendo algumas reflexões, colocando que as características sociais adequam o planejamento desses projetos aos interesses do sistema econômico e cultural instaurado. Segundo o autor não se pode construir um projeto de vida emancipador e autônomo dentro de um conformismo social.

A dissertação de Geuid Cavalcante da Silva Filho, defendida em 2018, em São Paulo, na UNINOVE, intitulada "Formação, projetos profissionais e projetos de vida: olhares dos estudantes do curso de técnico em administração integrado ao ensino médio do IFPI Campus de São Raimundo Nonato" fez uma investigação sobre os projetos profissionais e projetos de vida dos estudantes dos cursos de ensino médio integrado à educação profissional, oferecidos pelos Institutos Federais de Educação, Ciência e Tecnologia. Faz reflexões sobre projetos profissionais e projetos de vida à luz da Teoria Crítica da Escola de Frankfurt, 


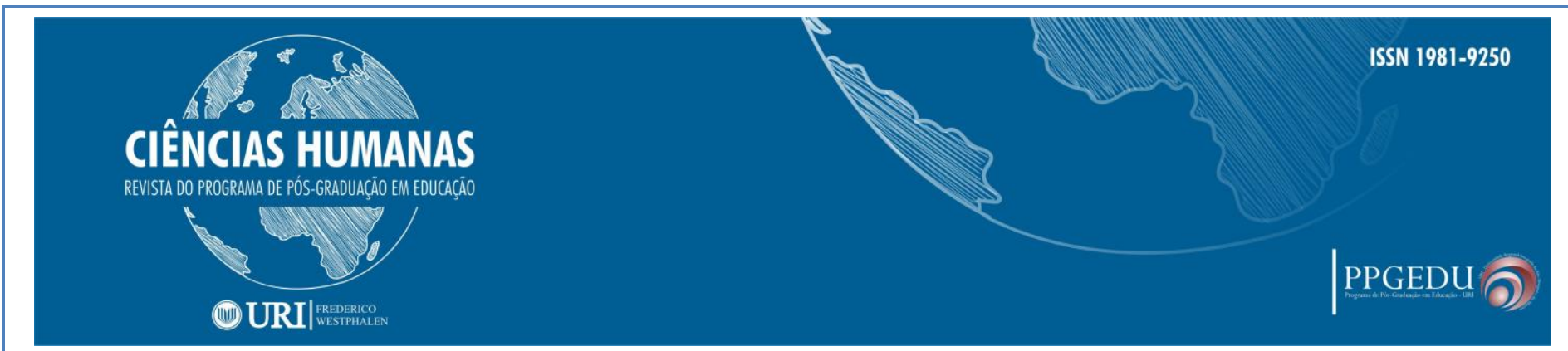

sobretudo o pensamento de Theodor Adorno, Max Horkheimer e Herbert Marcuse, além de estudiosos brasileiros que dão continuidade às reflexões desses três pensadores em seus estudos. Conciliando com as dissertações de Fodra (2016) e Silva (2017), Silva Filho (2018) enfatiza que os projetos de vida são associados aos valores que carregamos e que muitos jovens colocam seus projetos profissionais em posição central aos seus projetos de vida porque vivem imersos nas cobranças da sociedade. Às vezes tem-se uma meta, um sonho, mas nem sempre escolhemos livremente alcançá-los, vivendo muitas vezes em função de valores modelados a partir de um mundo exterior e imbuídos de conformismo social.

Assim percebemos que uma das maneiras de conceber os projetos de vida é associálos a escolha profissional, no entanto, essa não é a única maneira de entendê-los, aliás, encontramos autores que já refletem sobre como a escolha profissional está intimamente ligada a maneira do jovem estabelecer suas relações socioculturais, fazendo o termo projetos de vida não se relacionar apenas a projetos profissionais, pois, "é preciso problematizar outras dimensões da condição humana, como as escolhas afetivas, os projetos coletivos e as orientações subjetivas da vida individual" (ALVES, 2013, p.377).

\section{Os projetos de vida e a construção social do jovem}

A percepção de que o jovem se constrói a partir de suas relações socioculturais e econômicas e que isso influencia diretamente em suas trajetórias de vida vem ficando cada vez mais notório nas discussões sobre os projetos de vida. A dissertação de Tiago Ribeiro dos Anjos, defendida em 2017, em São Carlos, na UFSCAR, intitulada: "Projeto de vida e ENEM: uma análise do questionário socioeconômico e suas implicações para o ensino médio" teve por objetivo "analisar a relação entre os interesses dos alunos em participar do Exame Nacional do Ensino Médio, considerando aspectos sociais, econômicos e raciais, e a construção do projeto de vida de adolescentes de escolas públicas e privadas do Estado de São Paulo" (ANJOS, 2017, p. 13). Ela reforça entre os vários olhares para o tema projetos de vida (Paredes e Pecora, 2004; Soares, 2008; Pilon, 1996; Lachitim e Soares, 2011; Oliveira e Saldanha, 2010) concepções que se aproximam dessa construção. O autor define projetos de vida ancorado em Catão (2007): 


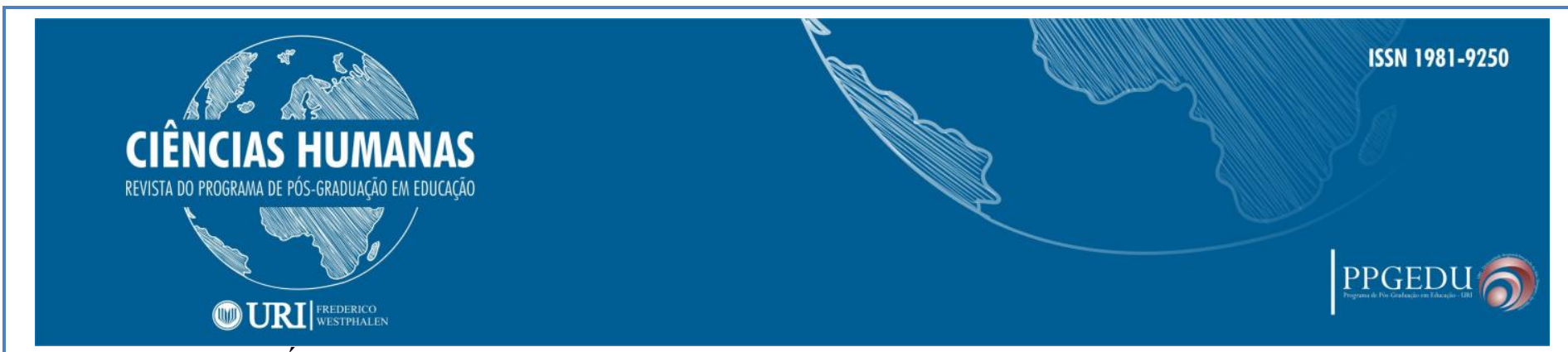

É possível identificar que a "falta de oportunidades sociais, políticas e culturais, convivendo em condições de violência, privação de alimento e habitação, falta de informações, orientações, e capacitação profissional, vivendo na condição de excluídos sociais" são condições em que muitos dos nossos adolescentes constroem suas expectativas futuras. Essa realidade é muitas vezes o único "local" possível de chegada para esses adolescentes caso nenhuma outra oportunidade seja ofertada. (ANJOS, 2017, p. 48).

Desta maneira, o autor tem uma concepção mais próxima das discussões da psicologia humana, reafirmando a construção do projeto de vida como uma condição psicossocial, uma forma de se colocar, interpretar e de se projetar no presente para modificar o futuro, fruto das experiências, vivências e oportunidades encontradas no contexto social.

Sendo assim, o projeto de vida também tem origens comuns com o próprio sujeito social, uma vez que o ser humano e o seu projeto de vida têm uma historicidade e sua construção é pautada dialeticamente entre o indivíduo e o mundo real (CATÃO, 2007). (ANJOS, 2017, p. 49).

Seguindo a mesma linha de pensamento, a pesquisa intitulada "Os desafios e limites na construção do projeto profissional dos jovens que frequentam o ensino médio público e privado", de Camila Ferreira Lopes Paiva, defendida em 2013, em Rio Claro, na UNESP, que teve por objetivo identificar o que compõe o projeto de vida de alunos do Ensino Médio público e privado, também constrói a concepção de projetos de vida numa visão mais psicológica. A partir da palavra projetos e dialogando com Machado (2000) e Dib e Castro (2010) propõe que, embora o termo sirva para designar elementos arquiteturais, o projeto também tem seu fundamento no modo como o sujeito e a sociedade se relacionam com o tempo e o devir (PAIVA, 2013). A autora aborda o conceito de projeto de vida em uma vertente psicológica, tomando como base o psicólogo cubano Hernández (1999). Para ele, um projeto de vida envolve, por um lado, o sujeito como detentor de uma personalidade interna, e por outro lado, o sujeito como um indivíduo social necessitando cumprir papéis na sociedade, submisso a normas e tradições culturais, com um posicionamento na estrutura social e que é afetado por todas estas condições gerais e outras específicas de seu contexto diário. A autora acrescenta ainda que "os elementos do capital social e cultural do jovem podem influenciar e condicionar a construção dos projetos de vida" (BOURDIAU, 1989; 1988), estabelecendo 


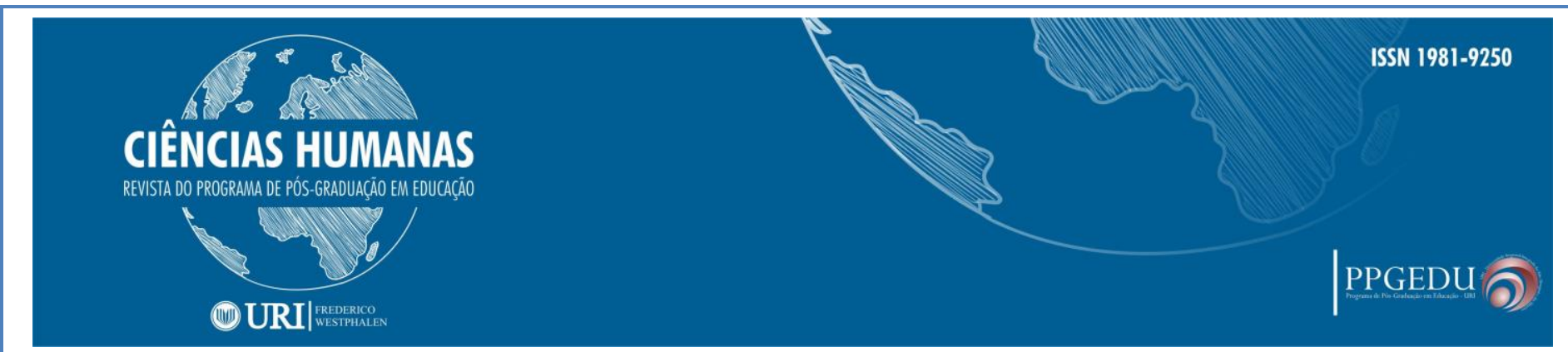

assim as possibilidades de atualizar as potencialidades individuais e elaborar maneiras para atingi- las, levando em consideração as experiências vividas, dialogando com Velho (1999).

Clércia Lorena do Amaral Shibuya através de sua dissertação "Do virtual ao real: implicações da internet nos projetos de vida do adolescente" defendida em 2012, em Recife, na UNICAMP, também ressalta a relação social e afetiva entre o sujeito e o universo. Para ela, projetos de vida vão além de uma dimensão profissional, se colocando numa dimensão mais abrangente:

Cabe-nos refletir acerca do que denominamos de projetos de vida. Aqui tem um sentido mais abrangente, não diz respeito apenas a uma dimensão profissional, mas à inclusão do sujeito no universo de relações sociais e afetivas com vistas à implementação de perspectivas para uma vida adulta. (SHIBUYA, 2012, p. 84)

Segundo Shibuya (2012), projeto de vida tem um sentido mais abrangente, não diz respeito apenas a uma dimensão profissional, mas envolve o crescimento do jovem. Ter um projeto de vida é viver com criatividade para ousar, espantar-se diante da realidade e tentar transformá-la, é imprimir uma marca pessoal na sociedade onde se está inserido.

\section{Os projetos de vida, a experiência e o campo de possibilidades}

As experiências particulares dos indivíduos, os vários modelos culturais, os lugares e espaços existentes e ocupados e a relação entre tudo isso também são contribuintes na construção dos projetos de vida e de seu envolvimento ou não nas possibilidades oferecidas pela sociedade. Esse diálogo entre esses espaços e experiências também tem sido objeto de apreciação em algumas pesquisas. Na dissertação de Antônia Aleksandra Mendes Oliveira, por exemplo, intitulada "Na terra da luz: O sol nasce para todos, mas a sombra é para poucos. Projetos de vida e campo de possibilidades de jovens das classes populares â Fortaleza â CE”, defendida em 2015, em Fortaleza, na UFC. teve-se o objetivo de conhecer as intenções, anseios, e, por conseguinte, dificuldades e possibilidades que os sujeitos têm, considerando suas trajetórias pessoais e suas experiências escolares. Há a percepção de um diálogo com as experiências vivenciadas pelos jovens nos vários espaços frequentados e suas metas. Seus sonhos e ideais de projetos de vida, aparecem em reflexões abordadas pela autora, demostrando como as classes desfavorecidas tornam como incerto as pretensões de vida no 


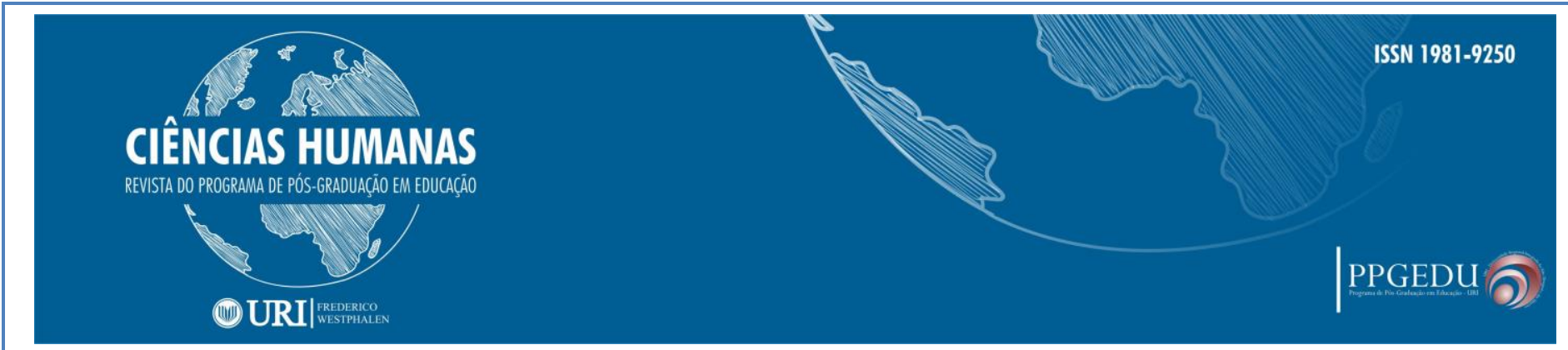

futuro, preocupando-se muito mais com o presente. Ela entende a categoria projeto de vida na visão de Velho (1997), estabelecendo um diálogo entre a sociologia das emoções e dos projetos, admitindo que:

A possibilidade de vivenciar e desfrutar determinadas sensações e experiências de vida está condicionada aos afetos e anseios que podem ser prestigiados e convalidados socialmente. (OLIVEIRA, 2015, p. 94).

Assim, a autora assegura que as experiências de vida estão intimamente condicionadas aos relacionamentos estabelecidos pelo jovem em seus vários convívios e que vão convalidar ou não suas escolhas de vida de acordo com suas possibilidades de relacionamento.

Compreendendo essa relação entre experiências e possibilidades, Terezinha de Jesus Lyrio Loureiro, na pesquisa intitulada "Juventude e projetos de futuro: possibilidades e sentidos do trabalho para os estudantes do Instituto Federal de Educação, Ciência e Tecnologia do Espírito Santo (Ifes)", defendida em 2013, em Vitória, na UFES, interrogou sobre como os jovens se posicionam frente as questões referentes aos significados do trabalho e como os projetos de vida se constroem na vida dos jovens estudantes, mesmo imersos num mundo de incertezas e fluidez. Apesar da autora se utilizar do termo projetos de futuro em seu título, ela constantemente o associa a projetos de vida como conceito semelhante. Existem outros autores que também usam projetos de futuro e projetos de vida numa mesma perspectiva, é o caso de Villas e Nonato (2014):

Estamos chamando de projeto de futuro a relação que os jovens têm com os planos que constroem para a vida, tanto no presente quanto em um futuro a pequeno, médio ou longo prazo (VILLAS e NONATO, 2014, p.10).

No entanto, existem outros autores que preferem usar projetos de futuro, referindo-se apenas aqueles projetos realmente pensados a longo prazo. Enquanto os projetos de vida se referem a todos os projetos realizados, mesmo que, a curto prazo, e que "implicam a capacidade de integrar o passado, o presente e o futuro, bem como as condições objetivas e subjetivas, articulando a unidade e a continuidade de uma biografia individual" (ALVES, 2013, p. 145). Apesar da justificativa utilizada pelos autores, consideremos que falar em projeto de futuro não é apropriado por conter aí uma redundância, pois a própria palavra projeto já traz implícita uma referência ao futuro, afinal, não é possível projetar o passado.

\begin{tabular}{l|c|c|c}
\hline Rev. Ciências Humanas & Frederico Westphalen, RS & Pg. 145-165 & Maio/Agosto 2019 \\
\hline
\end{tabular}




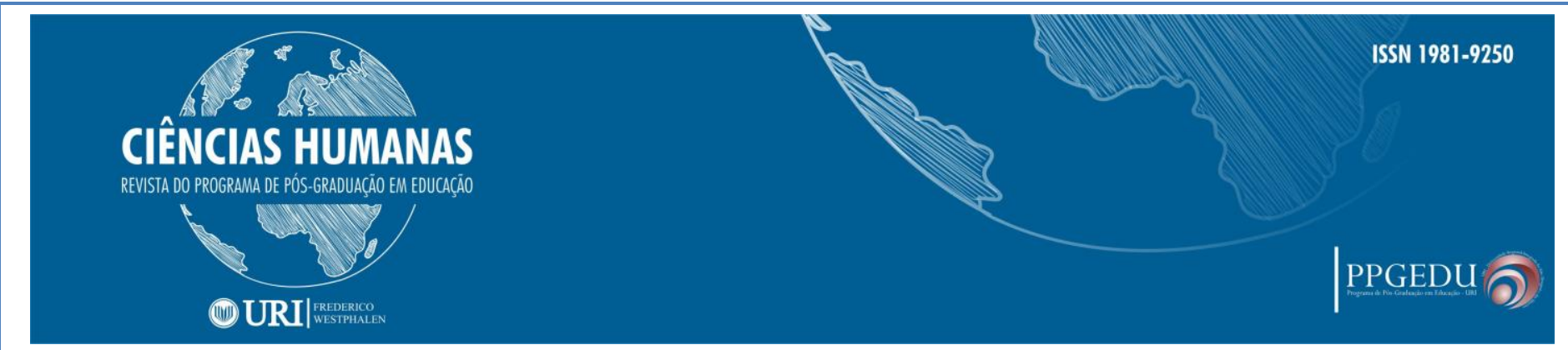

Para além dessa discussão, nota-se que Loureiro (2103) concebe projetos de vida, desenvolvendo o conceito de projetos segundo a visão de Schutz (1974) e Velho (1994), sendo o projeto definido como uma conduta organizada para atingir objetivos específicos e encontra-se ligado a um campo de possibilidades. Nessa perspectiva, a autora trabalha com o conceito de campo de possiblidades atrelada ao projeto de vida entendendo que a realização dos projetos depende das condições sócio históricas de cada sujeito.

Além de Loureiro (2013), Débora Linhares Silva em sua dissertação "Projetos de vida e estima de lugar: um estudo com jovens adolescentes de escolas públicas de Fortaleza/CE”, defendida em 2016 na Universidade Federal do Ceará (UFC), também tratou do campo de possibilidades como condição para se construir um projeto de vida. A dissertação buscou estabelecer relações entre projetos de vida de jovens adolescentes e a estima de lugar destes em relação às escolas públicas em que estudam. O conceito de "estima de lugar" é abordado pela autora segundo os aportes da Psicologia Ambiental (BOMFIM, 2010; TUAN, 1983):

\footnotetext{
Segundo os autores, lugar seria um espaço dotado de significado, sendo este proveniente da relação que se estabelece entre uma pessoa e um espaço. Ao se transformar em lugar, esse espaço adquire relevância e identificação, tornando- o passível de ser um gerador de afetos. Em todo esse processo, que transforma um espaço em lugar, existe a construção da chamada apropriação do espaço, que só é possível numa relação dialética entre pessoa e espaço e que, por sua vez, é inacabada e não fixa. (SILVA, 2016, p. 18).
}

Dessa forma, a autora analisa como as relações podem ser utilizadas como ferramentas potencializadoras de ação e resistência por jovens adolescentes, compreendendo que:

\footnotetext{
os projetos de vida não são apenas os aspectos concernentes à perspectiva de futuro ou a alcançar determinadas metas que atendam às demandas de uma sociedade pautada numa lógica de mercado/empregabilidade como sinônimos de realização pessoal (SILVA, 2016, p. 13).
}

Assim, as condições em que se constroem e executam os projetos de vida, "perpassa por ter possibilidades, por ter mesmo condições de refletir sobre sua própria vida e, no caso dos jovens, ter condições de ser-no-mundo, enquanto sujeito de ação, sujeito político." (SILVA, 2016, p. 13). Neste sentido: 


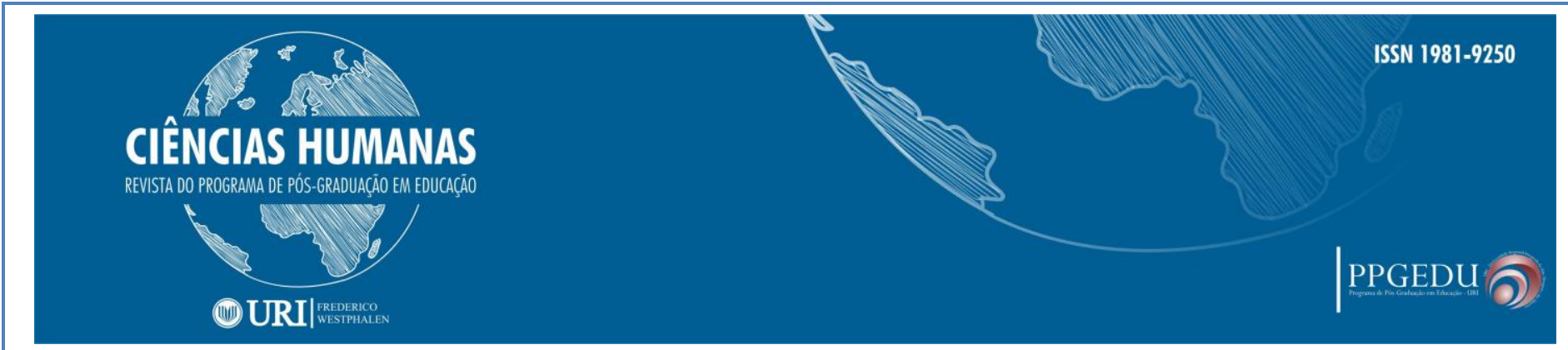

a construção do projeto de vida está vinculada a um conjunto de características de um sujeito relacionando-se com o que este atribui a si mesmo, aos outros e ao mundo. Logo, dá-se pelo constante diálogo indivíduo-coletivo articulando possíveis realizações que permitam a tomada de posição, organização e metas para alcançar um modo ou condição de vida (SILVA, 2016, p. 14).

No mesmo caminho de Silva (2016), Anderson Cinati, em sua dissertação "Escola, consumo e projetos de vida na visão de jovens estudantes de uma escola pública e outra privada no interior do estado de São Paulo", defendida em 2016, em São Carlos, na UFSCAR, baseia seus estudos em Hernandez (2002) e concebe o projeto de vida como uma busca existencial do sentido da vida, uma construção pessoal e social envolvida em subjetividades. Na sua pesquisa, procurou discutir as relações entre o consumo e o projeto de vida dos jovens pesquisados, na tentativa de entender como esses elementos os fazem repensar a educação de forma crítica. Entende que os diferentes estilos de vida refletem diretamente na construção dos projetos de vida.

Toda a construção, contudo, em relação ao projeto de vida, não se limita apenas às condições objetivas da vida, mas sim é um limiar entre a subjetividade e a objetividade, definidas a partir de uma reflexão crítica por meio de suas experiências de vida (CINATI, 2016, p. 25)

Nessa reflexão crítica das experiências da vida, o campo de possibilidades e limites psicossociais aparecem como variantes na construção dos projetos de vida. Da mesma forma, Cinatti (2016) acredita que a família tem papel importante, pois, mesmo não sendo a única responsável pelo desenvolvimento do jovem, surge como elemento de destaque sendo a primeira instituição na qual o jovem se desenvolve. Nos resultados da pesquisa de Cinatti (2016), a família permanece na vida dos jovens estudantes pesquisados, ainda que de modos diferentes, como instituição na qual todos se incluem. Referindo-se aos projetos de vida dos jovens, a família opera em duas frentes: ora incentivando o jovem a romper seus limites, ora incentivando a adaptação desse jovem dentro do contexto e das possibilidades vividas dentro do próprio contexto familiar.

\section{Os projetos de vida e os valores do presente}

Os projetos de vida aparecem em algumas dissertações analisadas atreladas aos valores adquiridos no tempo presente e no espaço familiar, nos grupos religiosos, escola ou

\begin{tabular}{l|c|c|c}
\hline Rev. Ciências Humanas & Frederico Westphalen, RS & Pg. 145-165 & Maio/Agosto 2019 \\
\hline
\end{tabular}

\begin{tabular}{l|l} 
Recebido em: 10/06/2019 & Aceito em: 16/08/2019
\end{tabular}




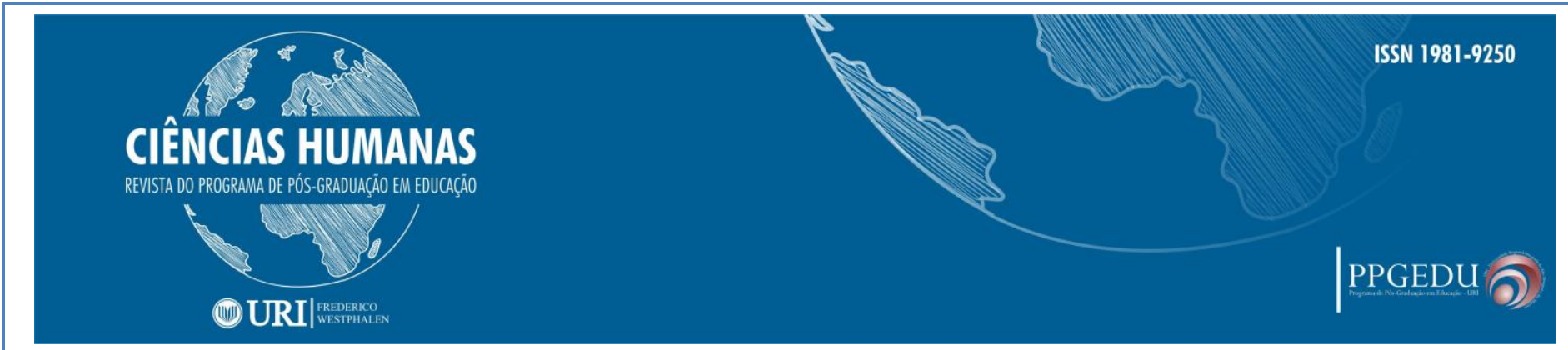

em outros espaços frequentados pelos jovens. Gilberto Luiz Mattielo Júnior em sua dissertação "O amanhã de quem cresce: influências e valores presentes na constituição de projetos de vida de jovens adolescentes de um curso técnico de uma instituição estadual", defendida em 2015, em Marília, na UNESP, investigou a relação entre projeto de vida, valores e influências internas e externas de alunos de um curso técnico estadual. Apresenta a ideia de projeto de vida com base em D’Aurea-Tardeli (2011) em uma perspectiva psicológica e social na qual o elemento essencial na construção da personalidade moral são as relações com a sociedade circundante. Cita o papel da família, da escola e da mídia nesse processo duplo que pode ser de ajuda ou de desincentivo e alienação. Nos resultados, a família foi um dos aspectos de destaque, pois, concluiu-se uma ligação direta entre as expectativas e preocupações com o presente e futuro, geralmente vinculados à família, aos estudos e à carreira. Em relação aos projetos de vida, "igualmente predominou uma auto orientação, ou seja, praticamente não houve projetos de vida direcionados ao bem-estar coletivo da comunidade" (MATTIELO JÚNIOR, 2015, p. 7).

De acordo com Alves (2013), a forma de lidar com o tempo influencia na forma como os sujeitos lidam com os projetos, ou seja, um jovem muito preocupado em aproveitar a vida no tempo presente tende a não se preocupar muito com o amanhã, do mesmo modo um jovem demasiado preocupado com o futuro pode perder oportunidades de viver o tempo presente. Por isso a importância do papel de instituições como a escola e família assumirem-se como mediadoras nesse processo de construção dos projetos, orientando os jovens sobre as escolhas presentes, a relação com o futuro e o bem-estar coletivo.

\section{Os projetos de vida, os projetos de futuro e os projetos vitais}

Alguns autores, utilizam outras expressões como sinônimos de projetos de vida, no entanto, na dissertação de Daniela Haertel Hurtado "Projetos de vida e projetos vitais: um estudo sobre projetos de jovens estudantes em condição de vulnerabilidade social da cidade de São Paulo”, defendida em 2012, em São Paulo na FE/USP, houve uma diferenciação entre ambos com base em Bundick (2009) e Damon (2009b). Construída com o objetivo de identificar os projetos de vida e projetos vitais éticos dos jovens estudantes com idade entre 16 e 18, anos em condição de vulnerabilidade social, de uma instituição pública de Ensino

\begin{tabular}{c|c|c|c}
\hline Rev. Ciências Humanas & Frederico Westphalen, RS & Pg. 145-165 & Maio/Agosto 2019 \\
\hline \multicolumn{2}{c}{ Recebido em: 10/06/2019 } & Aceito em: 16/08/2019
\end{tabular}




\section{CIÊNCIAS HUMANAS}

REVISTA DO PROGRAMA DE PÓS-GRADUAĞ̈O EM EDUCAĞ̄o

\section{(10)URI|}

Médio do estado de São Paulo, a pesquisa de Hurtado (2012) buscou compreender as principais características destes projetos, e se eles poderiam influenciar os demais objetivos e aspirações e a percepção de sentido e significado de suas vidas. Houve uma busca por diferenciar os conceitos de projetos de vida e projetos vitais dentro dos estudos da Psicologia positivista. Segundo a autora, baseando-se em Bundick (2009), o projeto de vida corresponde a um projeto idealizado a longo prazo com vistas no futuro, com grande significância, capaz de motivar e conferir sentido a existência do sujeito. Já o projeto vital é compreendido pela autora baseando-se em Damon (2009b), e diz que, apesar de também conferir significado a existência do sujeito e poder ser desenvolvido a longo prazo, corresponde aos objetivos que são essenciais na identidade do sujeito. Sendo assim, um projeto vital com finalidades éticas envolve exercício pleno da cidadania, conferindo sentido ético a si próprio e à sua existência na sociedade.

No entanto, como já foi citado anteriormente, alguns autores utilizam projetos de vida e projetos de futuro como sinônimos. É o caso da dissertação de Kamila Costa Sousa "Percursos e projetos de vida das juventudes egressas da escola do campo", defendida em 2016, em Fortaleza, na UFC, que teve o objetivo de compreender como a Educação do Campo repercute nos percursos iniciados pelos jovens egressos e nos seus projetos de vida, após a conclusão do ensino médio na escola do campo. Aqui, diferentemente de Hurtado (2012), Sousa (2016) preferiu utilizar projetos de vida e projetos de futuro como sinônimos, em uma perspectiva sociológica onde estes são construídos de acordo com a dinâmica social que afeta os jovens.

Vejo as táticas como as maneiras que favoreceram ou favoreceram a realização dos seus projetos de vida, que são projetos de futuro, mas também projetos do presente. (SOUSA, 2016, p. 185).

O fato de os projetos de futuro dialogarem com os projetos do presente, complementa a concepção de que os projetos de vida fazem parte de uma construção total do indivíduo, seja ele jovem ou adulto, onde a dinâmica social, cultural e histórica influencia, favorecendo ou não as construções das trajetórias. Aqui a autora faz um bom exercício para escapar à nossa crítica ao termo projeto de futuro ao afirmar que os projetos são do futuro, mas também do 


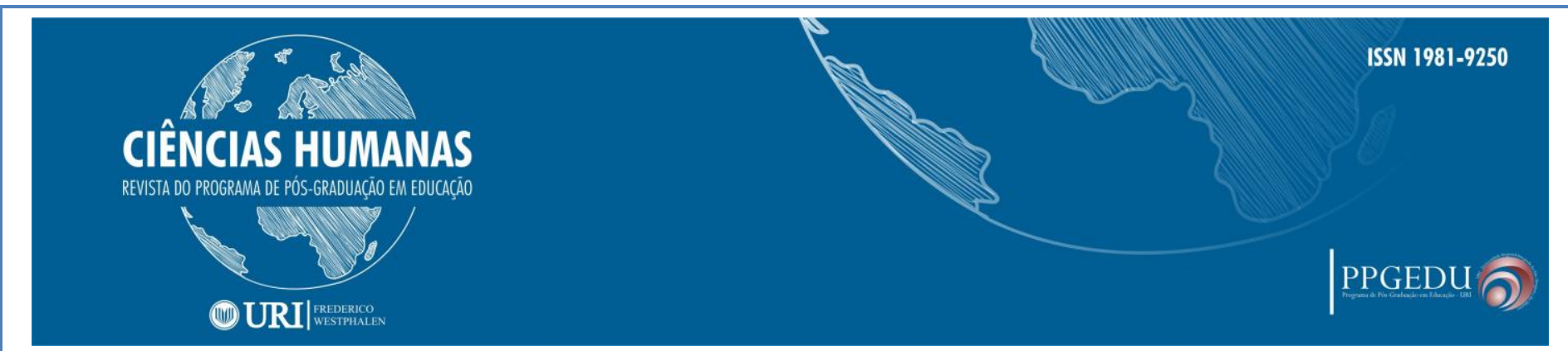

presente, o que concordamos, afinal, a vida também acontece no presente. Isso reforça nossa premissa de que os projetos de vida precisam articular passado, presente e futuro.

As construções de trajetórias individuais podem afetar o jovem indo além das mudanças internas, podendo promover mudanças no mundo. É o que diz Hanna Cebel Danza em sua dissertação "Projetos de vida e educação moral: um estudo na perspectiva da teoria dos modelos organizadores do pensamento", defendida em 2014, em São Paulo, na FE/USP, que teve como objetivo "investigar os projetos de vida de jovens em idade escolar juntamente com os valores que os subjazem" (DANZA, 2014, p. 9). Danza (2014) fez uma construção teórica da concepção de projetos de vida baseando-se nas seguintes dimensões: dimensão futura, criação, a busca de sentido, a pessoalidade, os valores, as condutas de antecipação e de planejamento, o campo de possibilidades e a realização do projeto em si. Fala do projeto de vida como forma de promover mudanças no mundo, mudando a trajetória de um percurso já dado, como modo de vencer a inercia predefinida pelo que o mundo e os nossos convívios e situações sociais nos propõem. Trabalha com os termos purpose do inglês denominado por Araújo como projetos vitais (Araújo, 2009), mas cita que Damon (2009) e vai além, dizendo que projeto vital é um objetivo a longo prazo, indo além de um objetivo de sair no sábado à noite. Não é uma mera meta.

Segundo Danza (2014), os projetos de vida encarnam a perspectiva moral do sujeito, traduzido em sentimentos, emoções, valores, sonhos, mas também, em metas e ações permeadas por esses conceitos. Ademais, insere um elemento novo à discussão, relativo ao aumento da postergação das escolhas dos jovens em função das incertezas e instabilidades do mundo contemporâneo, citando inclusive a ausência de projetos de vida na vida de alguns jovens, que Alves (2013) denomina de sem projetos ou fora de projeto.

\section{CONCLUSÃO}

Brevemente esta análise nos mostrou que, embora emergente, o conceito de projetos de vida já acumula discussões e reflexões importantes, apesar do pequeno número de pesquisadores que têm se debruçado a conhecer mais sobre o tema e em sua construção. Outro aspecto relevante é que boa parte dessas pesquisas têm buscado compreender o conceito no 


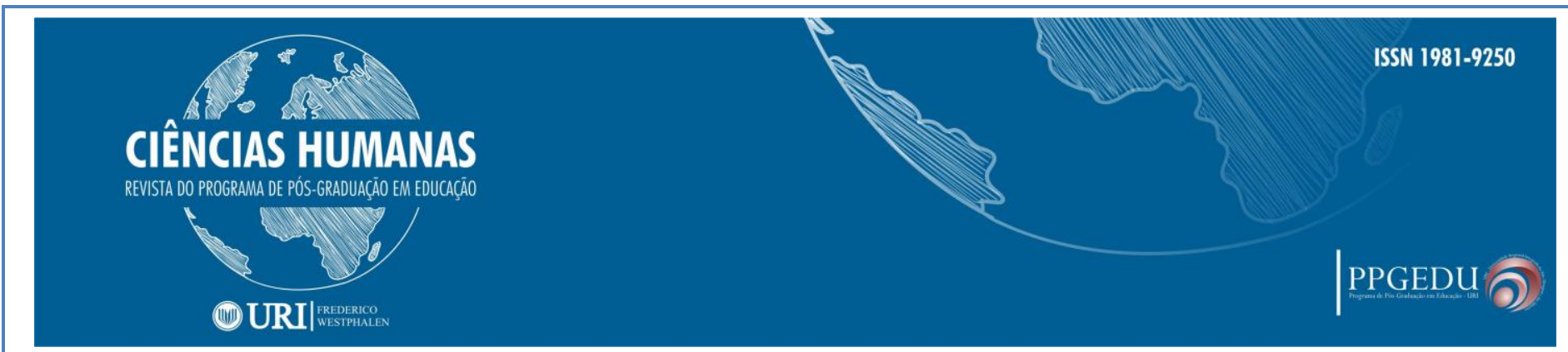

contexto educacional, embora essa compreensão pode variar de acordo com os referencias teóricos.

Das dissertações analisadas, por mais que 05 delas tenham se concentrado no projeto de vida na perspectiva profissional, essas compreendem que o projeto profissional é apenas um dos projetos construídos pelos jovens. Apenas uma dissertação se constrói tomando projetos profissionais como sinônimo de projetos de vida. As demais entendem que os projetos de vida se constituem como resultado da construção do sujeito na sociedade. Também observamos que, apesar da categoria projetos de vida aparecer associada a outros termos, as análises comprovaram que os autores tomaram essa categoria como central em suas análises. As pesquisas evidenciam que os projetos de vida abarcam questões sociais, culturais e profissionais numa perspectiva de envolvimento das relações de espaço, tempo e dos sujeitos envolvidos.

Sendo assim, as diversas concepções de projetos de vida, ou mesmo a falta ou a postergação deles na vida dos jovens, está intimamente ligado ao contexto histórico e sociocultural onde o jovem está inserido, bem como aos valores construídos neles seja na família, na escola ou nos vários grupos nos quais convivem. Fica claro também que o modo como o jovem é recebido, reconhecido e formado nos espaços que frequenta, cria neles mecanismos de adaptação, postergação, resistência ou luta como resultado de suas escolhas.

O fato de os projetos de vida estarem sendo discutidos no espaço escolar nos chama a atenção porque, de acordo com as experiências vividas, pode-se construir nos jovens aspectos de autonomia e protagonismo diante das condições que lhes são impostas, mas também pode gerar a acomodação e o desinteresse. Portanto, é de suma importância nas escolas, especialmente as de Ensino Médio que estão inserindo a discussão dos projetos de vida, seja por meio de disciplinas eletivas, seja por meio outras metodologias e estratégias, o foco no sujeito para o qual é direcionada a discussão: o jovem. Este não pode tomar seus projetos apenas como um direcionamento profissional ou mesmo como uma tarefa escolar, mas compreendê-los em sua magnitude, como um meio de se perceber dentro da sua comunidade, dos seus espaços de atuação e movimentá-los para criar modos de vencer as limitações e lutar por condições mais dignas que lhes permitam "ser alguém na vida", partindo do ponto de vista das suas reais escolhas e sonhos. 


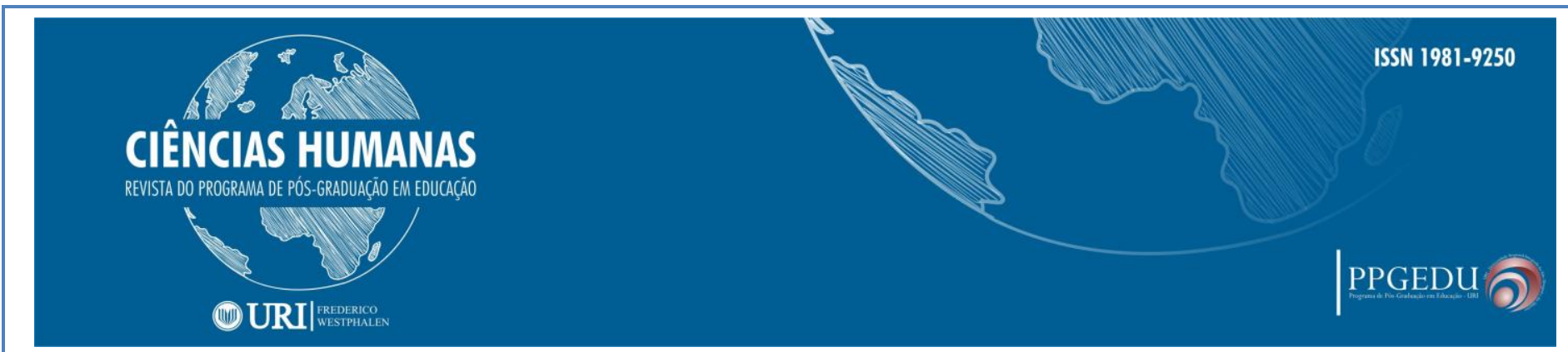

Esta análise foi uma tentativa de sistematizar algumas contribuições trazidas por pesquisadores que se aventuraram a trabalhar com esta categoria. Ainda há muito o que se compreender sobre este conceito que, como sugerimos no título, encontra-se em construção.

\section{REFERÊNCIAS}

ALVES, M. Z.; DAYRELL, J.. Ser alguém na vida: um estudo sobre jovens do meio rural e seus projetos de vida. Educ. Pesqui., São Paulo, v. 41, n. 02, p. 375-390, abr./jun. 2015. http://www.scielo.br/pdf/ep/v41n2/1517-9702-ep-41-2-0375.pdf. 04/05/2019.

ALVES, M. Z. Ser alguém na vida: condição juvenil e projetos de vida de jovens moradores de um município rural da microrregião de Governador Valadares-MG. 2013. 213f. Tese (Doutorado em Educação) - Universidade Federal de Minas Gerais, Belo Horizonte, 2013.

ANJOS, T. R. Projeto de vida e ENEM: uma análise do questionário socioeconômico e suas implicações para o ensino médio. 2017. 153f. Dissertação (Mestrado Profissional em Educação) - Universidade Federal de São Carlos, São Carlos, 2017.

BOUTINET, J. Antropologia do projeto. Porto Alegre: Artmed, 2002.

CATÃO, M. F. M. Projeto de Vida em Construção na exclusão Inserção Social. João Pessoa: UFPB, Ed. Universitária. 2001. Apud: SEQUEIRA, M. V. M.; CATÃO,

M. F. F. M. Adolescentes em processo de exclusão e a construção do projeto de vida. Anais do V Jornada Internacional e III Conferência Brasileira sobre Representações Sociais.

Brasília: 1 CD-ROOM, 2007.

CINATI, A. Escola, consumo e projetos de vida na visão de jovens estudantes de uma escola pública e outra privada no interior do estado de São Paulo. 2016. 147f. Dissertação (Mestrado Profissional em Educação) - Universidade Federal de São Carlos, São Carlos, 2016.

DANZA, H. C. Projetos de vida e educação moral: um estudo na perspectiva da teoria dos modelos organizadores do pensamento. 2014. 261f. Dissertação (mestrado) - Faculdade de Educação/USP, São Paulo, 2014.

DAYRELL, J. Pedagogia da juventude. A escola precisa reconhecer o jovem por trás do aluno e adaptar a ele seus processos educativos. In:

http://www.ondajovem.com.br/acervo/1/pedagogia-da-juventude. 04/05/2019.

FODRA, S. M. O projeto de vida no ensino médio: o olhar dos professores de História. 2016. 175f. Dissertação (Mestrado em Educação) - Pontifícia Universidade Católica de São Paulo, São Paulo, 2016.

HERNÁNDEZ, O.D. Sentido de vida, sociedad y proyectos de vida. In: HERNÁNDEZ,

\begin{tabular}{|l|c|c|c|} 
Rev. Ciências Humanas & Frederico Westphalen, RS & Pg. 145-165 & Maio/Agosto 2019
\end{tabular}

\begin{tabular}{l|l} 
Recebido em: 10/06/2019 & Aceito em: 16/08/2019
\end{tabular}




\section{CIÊNCIAS HUMANAS}

REVISTA DO PROGRAMA DE PÓS-GRADUAĞ̈O EM EDUCAĞ̄o

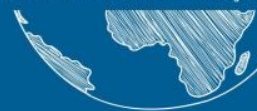

\section{(10)URI|}

O.D. Ética y Sociedad. La Habana: Edit. Félis Varela, 2002. p. 1-42. Disponível em: < http://biblioteca.clacso.edu.ar/ar/libros/cuba/cips/caudales05/Caudales/ARTICULOS/Ar ticulosPDF/07D054.pdf>. Acesso em: 17 de jul. 2015.

HURTADO, D. H. Projetos de vida e projetos vitais: um estudo sobre projetos de jovens estudantes em condição de vulnerabilidade social da cidade de São Paulo. 2012. 170 f. Dissertação (Mestrado em Educação) - Faculdade de Educação USP, São Paulo, 2012.

LEITE, A. C. C. de A. A noção de projeto na educação: o "método de projeto" de William Heard Kilpatrick. 2007. 72 f. Dissertação (Mestrado em Educação) - Pontifícia Universidade Católica de São Paulo, São Paulo, 2007.

LEÓN, O. D. Adolescência e Juventude: das noções às abordagens. AÇÃO EDUCATIVA,São Paulo. Disponível em: ttp://library.fes.de/pdffiles/bueros/brasilien/05623.pdf. 04/05/2019.

LOUREIRO, T. de J. L. Juventude e projetos de futuro: possibilidades e sentidos do trabalho para os estudantes do Instituto Federal de Educação, Ciência e Tecnologia do Espírito Santo (Ifes). 2013, 103 f. Dissertação (Mestrado em Psicologia) - Universidade Federal do Espírito Santo. Vitória, 2013.

MACHADO, N. J. Educação: Projetos e Valores. São Paulo: Escrituras editoras, 2000.

MATTIELO JUNIOR, G. L. O amanhã de quem cresce: influências e valores presentes na constituição de projetos de vida de jovens adolescentes de um curso técnico de uma instituição estadual. 2015. 141f. Dissertação (mestrado) - Universidade Estadual Paulista Júlio de Mesquita Filho, Faculdade de Filosofia e Ciências, 2015.

OLIVEIRA, A. A. M. Na terra da luz: o sol nasce para todos, mas a sombra é para poucos. Projetos de vida e campo de possibilidades de jovens das classes populares. 2015. $170 \mathrm{f}$. Dissertação (Mestrado em Sociologia da Educação) - Universidade Federal do Ceará, Fortaleza, 2012.

PAIVA, C. F. L. Os desafios e limites na construção do projeto profissional dos jovens que frequentam o ensino médio público e privado. 2013. 126 f. Dissertação (mestrado) - Universidade Estadual Paulista Júlio de Mesquita Filho, Instituto de Biociências de Rio Claro, 2013.

SHIBUYA, C. L. do A. Do virtual ao real: implicações da internet nos projetos de vida do adolescente. 2012. 124 f. Dissertação (Mestrado em Psicologia Clínica) - Universidade Católica de Pernambuco, Recife, 2012.

SILVA FILHO, G. C. Formação, projetos profissionais e projetos de vida: olhares dos estudantes do curso de técnico em administração integrado ao ensino médio do IFPI - 


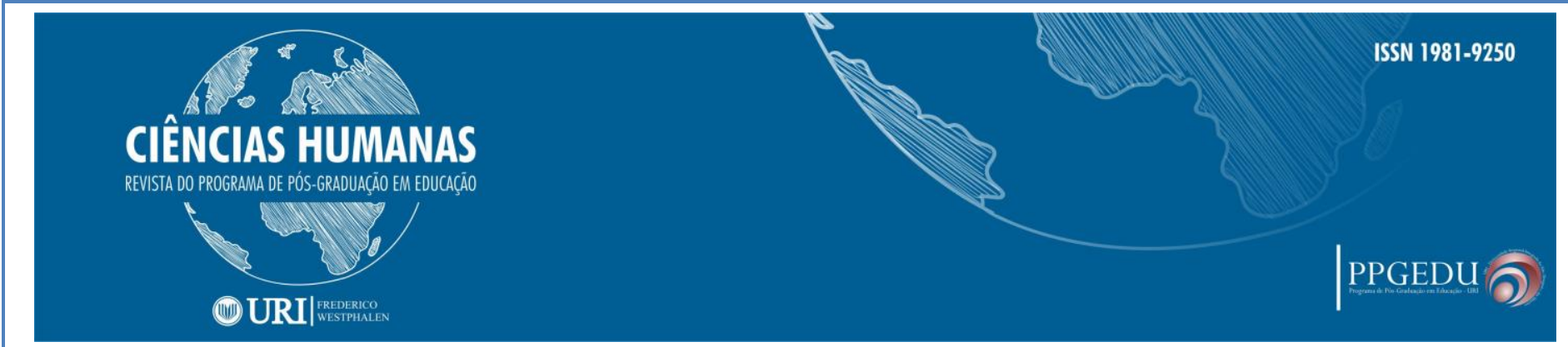

Campus de São Raimundo Nonato. 2018. 240f. Dissertação (Programa de Pós-Graduação em Educação) - Universidade Nove de Julho, 2018, São Paulo.

SILVA, A. B. Escolhas possíveis em futuros incertos: a escola e a construção do projeto de vida profissional na adolescência. 2017. 150f. Dissertação (Programa de Pós- Graduação em Educação) - Universidade Nove de Julho, São Paulo, 2017.

SILVA, D. L. Projetos de vida e estima de lugar: um estudo com jovens adolescentes de escolas públicas de Fortaleza/CE. 2016. 142f. Dissertação (Mestrado em Psicologia) - Universidade Federal do Ceará, Fortaleza, 2016.

SOARES, M. Linguagem e escola: uma perspectiva social. $18^{\mathrm{a}}$ ed. São Paulo: Contexto, 2017.

SOUSA, K. C. Percursos e projetos de vida das juventudes egressas da escola do campo. 2016. 215f. Dissertação (Mestrado em Educação) - Universidade Federal do Ceará, Fortaleza, 2016.

VILLAS, S.; NONATO, S. Juventude e projetos de Futuro. In: Cadernos temáticos: juventude brasileira e Ensino Médio / Licinia Maria Correa, Maria Zenaide Alves, Carla Linhares Maia, organizadoras. - Belo Horizonte: Editora UFMG, 2014.

VELHO, G. Projeto e metamorfose: antropologia das sociedades complexas. - $3^{\mathrm{a}}$ ed.- Rio de Janeiro: Jorge Zahar Ed., 2003. 